Journal of Humanities, Social and Management Sciences (JHSMS) eISSN: 2788-4791 (online) https://doi.org/10.47264/idea.jhsms/2.2.18

Vol. 2, No. 2 (July-December 2021), 240-254

https://www.ideapublishers.org/index.php/jhsms

Research Article

\title{
Real, compared to what? Insertability of constrained realemes in Dave Eggers' What is the What
}

\author{
Muhammad Uzair Khan ${ }^{1 *} \mid$ Saleem Akhtar Khan ${ }^{2}$ \\ 1. Department of English, Dartmouth College Hanover, New Hampshire, United States. \\ 2. Department of English, University of Sialkot, Sialkot, Pakistan. \\ *Corresponding Author Email: uzairkhan313@gmail.com
}

Received: September 21, 2021

Published: December 31, 2021

\begin{abstract}
The paper examines Eggers' What is the What (2006) that has problematically been called an autobiographical novel and memoire, narrating Valentino's chequered past as one of Sudanese Lost Boys. The text yields potential perspectives that demand scrutiny for understanding of the fascinating reciprocity between fictionality and historicity. The article engages theorizations of the complex coalescence offered by Zohar (1980) and McHale (1987) to benchmark the thematic dimensions of the selected text against the cutting-edge postulates. In addition, Valentino's preface to the "novel", engaging with the purpose of his collaborative working with Eggers, and Eggers' essay "It was just boys walking" (2004), negotiating the genesis of the project, have also been used as a methodological touchstone. The analysis vindicates the correspondence between the fictional and the historical versions, albeit the author has fictionalized gaps of Valentino's historicized life. Thus, Eggers' text consummates blurring by encompassing both the thematic dimensions, fusing fiction and fact, and the structural schemas, mixing the techniques of different genre traditions, inasmuch as his work exhibits a hermeneutic playfulness found at the heart of the aesthetics of postmodern and 9/11 fiction.
\end{abstract}

Keywords: fiction, history, insertability, constrained realemes, 9/11, postmodern, poetics, hermeneutics.

\section{How to Cite:}

Khan, M. U. \& Khan, S. A. (2021). Real, compared to what? Insertability of constrained realemes in Dave Eggers' What is the What. Journal of Humanities, Social and Management Sciences (JHSMS), 2(2), 240-254. https://doi.org/10.47264/idea.jhsms/2.2.18

Publisher's Note: IDEA PUBLISHERS (IDEA Publications Group) stands neutral regarding jurisdictional claims in the published maps and institutional affiliations.

Copyright: @ 2021 The Author(s), published by IDEA PUBLISHERS (IDEA Publications Group).

Licensing: This is an Open Access article published under the Creative Commons AttributionNonCommercial 4.0 International License (http://creativecommons.org/licenses/by-nc/4.0/) 


\section{Introduction}

"The Oranging of America...is fiction, and its content derives entirely from my imagination. Where I have used real names or what seem to be physical descriptions of real people, it is done purely in the interest of fiction. In any serious sense any similarities between these stories and the real lives of any person living or dead are unintended and coincidental."

- Max Apple's The Oranging of America and Other Stories, 1976

Situatedness of the literary writings on the cusp between factuality and fictionality is an obvious, also intriguing, factor that makes the representational frames found in the historical fictional narratives remain stretched under the pressure of the perplexing reciprocations between the realms of fact and fiction. Ironically, the kind of inevitable phantasmagorical framing adds to functionality of literature by bringing more curiosity to it.

The notion that literature is a sincere description and depiction of reality is still detectable in literary criticism and poetics and it is because of this view that a wrong perception has established that literature has always been free from any constraints, so far as framing of reality is concerned (Zohar, 1980). Similarly, the definition of novel that it is a realist representation of life and statements like 'poetry is divine, and fiction is human' are in every novelist's back of the head and are responsible for his/her goal to depict reality and actuality in fictional works. The realist approaches in fictional narratives range from social, political and historical to psychological and hysterical, among others. So, it is the prime objective and aim of a novelist to represent reality but the relationship between actuality and fictionality is very tricky, especially in the case of the novels dealing with historical reality, real life figures and incidents. The modern world has put a lot of (un)due burden on the fiction writers' shoulders as we see legal constraints binding on them, such as label laws, which make them conscious, or sometimes over-conscious, about the nature of the job they are involved in. So, in the present era, writers are supposed to give mock disclaimers at the beginning of their anti-mimetic works of fiction in order to keep them safe from label laws and plausible lawsuits.

This book is a work of fiction and entirely a product of the writer's imagination so, any resemblance with an event or character, living or dead, would be entirely unintentional and co-incidental - such is the text of the modern-day disclaimers that are loaded with mimetic preconceptions. Here, a question arises that if it is such a risky business then why the fiction writers play with the fire. They do so because giving reference to real life characters and especially playing with the names of the celebrities have two folded significances. Firstly, these names have an appeal for the readers and secondly, such references have an air of scandal about them. In fact, this practice is a double-edged knife that cuts through both ways. Moreover, the source of the scandal is ontological in nature as the boundaries between real and fictional worlds are being violated. An ontological scandal is when real world figures are inserted in a fictional world setting where they interact with fictional characters, as well as when real life characters interact with each other in a fictional situation (McHale, 1987).

The result of this ontological scandal is the invention of characters that are trans-world identical who send shockwaves throughout the world's ontological structures. This type of trans-world identical figures is typical of realist historical fiction. This creates a double-dicker-structure of reference, also known as the universal structure of (literary) reference where an internal e.g., 
fictional field of reference and an external e.g., real world field of reference overlap and interpenetrate (McHale, 1987). Here, McHale supports the notion of Zohar (1980) who is of the view that in cultural texts, the repertoriness of realemes is compatible with the traditional view of fictionality and even more so with the idea of internal field of reference related to reality in literature (Zohar, 1980). But apart from these universally applicable structures of reference, there are secondary functions of realemes as well which depend on varied local, cultural, generic and spatial norms that are more constraining, such as label laws in the postmodern age. Among all these constraints binding on a fiction writer, some are genre specific, some age, some cultural and some are historical, among which we are looking for historical constraints in Dave Eggers' What is the What (2006).

The stance of the researchers is this paper is that postmodern fiction is marked by a playful hermeneutic in and out of genres that can be seen in Eggers attempt of mixing fiction with nonfiction. He also seems to have fictionalized on the "dark areas" of Valentino Achak Deng's life in Sudan and in America as a migrant in the shadow of the local events like Sudanese Civil War, as well as other international events of significance such as 9/11. In order to prove their point, the researchers have set their objectives. The aim of the paper, firstly, is to know how are the repertoires of historical realemes created for "traditional" and "classic" historical fiction; secondly, to highlight those constraints that govern the insertion of historical realemes in 9/11 historical fiction (What is the What) and thirdly, to gauge how postmodernist practices of writing fiction measure up against the "classic" tradition. In order to achieve the mentioned objectives, the researchers try to answer the following research questions:

a) What classic historical realemes are being observed or violated by Eggers in What is the What?

b) To what extent postmodern generic constraints can be found in Eggers' What is the What?

c) How do the postmodern fictional practices measure-up against the "classic" tradition in post-9/11 fiction?

The article is significant in terms of exploring the relationship between postmodern aesthetics and the aesthetics of the 9/11 fiction as the latter borrows much of its postulates from postmodernism. Moreover, dealing with history while creating historical fiction in modern times has lots of inconsistencies that need theoretical backing and then the theoretical underpinnings' usage needs identification in literary texts and it is what the researchers intend to do. The article is also significant as the reception of fiction dealing with real life characters has gained prominence in the aftermath of political conflicts of the recent human history. In such a scenario, it is important to dig out what kind of freedom is available to a novelist for fictionalizing the reality and that can only be determined by looking at the insertion of historical realemes by the writers in the historical fictional narratives. This analysis will provide a theoretical model to the students of literature interested in deconstructing the historiography of historical novels.

For the purpose to answer the above-mentioned research questions and in order to achieve the objectives of the research, the article, first of all, carries out a review of relevant literature that provides our claim a solid background. The methodology section determines the step-by-step procedure followed by the researchers during analysis of the primary text. Guided by the procedure laid out in the research methodology, the researchers have carried out the analysis 
of the text in light of the theoretical underpinnings and postulates specified in the theoretical framework portion of the article. The conclusion section summarizes the major findings of the analysis and discussion and tries to answer the research questions briefly. It also suggests implications for further research.

\section{Literature review}

Max Apple's disclaimer given in the epigraph of this article is from his collection of short stories The Oranging of America and other stories (1976). The statement is not a parody, but we must pay attention to the choice of his words. Such mocking disclaimers indicate the antimimetic nature of historical fiction. The real motive behind the need for such wording is the legal constraint because his stories bear characters that have been borrowed from real life. In the main story, "The Oranging of America", there is, as a character, the founder of a chain of roadside restaurants and motels named Howard Johnson, and another character with the name Robert Frost, a famous American poet. In "Inside Norman Mailer," there is this belligerent novelist and journalist with the name Norman Mailer. "Understanding Alvarado" features a Cuban dictator named Fidel Castro, hence the need for an especially equivocal disclaimer on the preliminary pages (Apple, 1976). While inserting the real people in the fiction, often the highly "charged" figures are preferred; figures rich in associations for most readers who are able to excite strong reactions of attraction or repulsion: Richard Nixon, the Kennedy brothers, Lenin, Chairman Mao, Rudolph Hess, Sigmund Freud, Trotsky, Malcolm X, Idi Amin, Sanjay Gandhi, Che Guevara, and Norman Mailer. Many other real-life people manipulated in this way include political leaders such as Abraham Lincoln, Warren G. Harding, Walter Mellon, Walter Rathenau, and Nelson Rockefeller; artists for example Paul Klee, Chagall, and Picasso; writers and thinkers such as Rossetti, Swinburne, Ruskin, Kafka, Max Brod, Wittgenstein, Shklovsky, Marcel Proust, Gertrude Stein, Joyce, Lawrence, Yeats, Pound, Milton, and Lord Byron; and media "stars" such as Mickey Rooney, Walt Disney, and the tennis star Ilie Nastase (McHale, 1987).

Not only does the presence of figures in texts like these violate the fictional-world/real-world boundary, but often multiply the ontological scandal by staging unhistorical hostilities between two or even more real-world figures: between Kafka and Wittgenstein in Davenport's "Aeroplanes at Brescia" (from Tatlin!, 1974); between Richard Nixon and Ethel Rosenberg in The Public Burning(1977); between John Milton and Thomas Urquhart (the translator of Rabelais) in Alasdair Gray's "Logopandocy" (from Unlikely Stories, Mostly, 1983); between Kennedy and Mailer in Abish's "The Istanbul Papers" (from Minds Meet, 1975); and, in Doctorow's Ragtime (1975), between various pairs of historical celebrities-Evelyn Nesbit and Emma Goldmann, Harry K.Thaw and Harry Houdini, Houdini and the Archduke Franz Ferdinand, and so on (McHale, 1987).

Against such a backdrop, inserting Valentino Achak Deng's (a real-life figure) story in fiction was a challenging task. But Eggers was the right person for the job as he had the experience of collecting other such life narratives in the past, for example converting the oral recordings of American teachers at public schools into Teachers Have It Easy: The Big Sacrifices and Small Salaries of American Teachers (2005). It is a similar book, in terms of methodology, by the author that was the result of his cooperation with Daniel Moulthrop (a public-school teacher) and with Nínive C. Calegari (the director of Valencia 826 schooling project). The purpose was to "create a book that would explain teachers' lives and make a case for better teacher 
compensation" (McSweeney's). ${ }^{1}$ From among the American public-school teachers, potential interviewees were searched for and reached through a website called McSweeney's, so that the volunteers could be interviewed "about their lives and their economic struggles" (McSweeney's). The book is a wonderful attempt, receiving high critical acclaim, as well as the utmost attention of teachers throughout America as it highlights the economic problems of American public-school teachers, especially, the issue of respect and professionalism among others (Moulthrop, et. al., 2005).

The authors, very convincingly, debunk several myths about teachers, their salaries and their lifestyle. One such myth is that the teachers get the summers off. But no one acknowledges the several hours they put into revising the curriculum of the courses they teach. In fact, 23 percent are compelled to take classes even in the summer that is mandatory for their promotion. Another 42 percent of the teachers are required to teach at summer schools etc. for which they are paid meagerly, if they are paid at all. To state the reality of summer vacations in an ironic and funny way, would definitely be like the title of Suhel Sheikh's to Clarify: Teachers are not off for the Summer, They are in Recovery $(2020)^{2}$. The book also compares one working day of a teacher and a pharmaceutical sales representative who gets $\$ 391.30$ while a teacher would be paid $\$ 256.00$. The authors also enlist several reforms for the uplift of teachers' lives and for the betterment of education at the end of the book (Moulthrop, et. al., 2005). It is a good read for anyone who is interested in the American education system, lives of the public-school teachers and recommendations for revolutionizing education. Although, the book is not related in theme and content with the work in question, but we reviewed it for it belongs to the same genre of testimonio.

What is the What is a peculiar kind of work that refuses categorization at first appearance, a postmodern feature, but when analysed deeply, it poses out to be a different genre altogether. Because of this feature, the book can rightly be termed a "miscellany" due to its blended form and genre. In this regard, the book holds an interesting parallel with the Latin American Genre called "testimonio". The collaborative method of working between Eggers and Valentino is the first aspect of this parallelism. This type of collaborative working method is not new and can be traced back to the 1966 published biography titled Biografía de un Cimarrón (Biography of a Runaway Slave) that was the result of collaboration between Estaban Montejo (a runaway Cuban slave) and Miguel Barnet (an anthropologist). Born to a slave family, Montejo's life story is very tragic and inspiring at the same time. He ran away and spent many years as a fugitive when finally, he entered the War of Independence of Cuba in 1898. Like Valentino, he also wanted to recount his story and like him, upon realizing the inefficiency of his language skills, decided to seek out the help of a writer, and in his case, consulted Barnet (Barnet, 1966).

Can Literature Promote Justice?(2006) is the title, in the form of a question, of Kimberely Nance's book on the study of testimonio, in the introduction of which she writes: "Barnet chose to [...] write in the first person voice of his speaking subject [...] The technique became a commonplace of Latin American testimonio" (Nance, 2006: 1). The project, as asserted by Barnet, "was more than the life story of an individual", rather, he insisted instead that, the project "gave voice to an entire class of people whose history had been ignored". (Nance, 2006: 1). The first-person narrative technique of Barnet is yet another parallel-apart from the collaborative efforts - between the genre and Eggers narrative style. However, no matter how fascinating the collaborative idea appears, it is not as easy a task as it may sound, especially for the authors. Nance (2006) highlights the point by saying that: 
...like all participants in the testimonial project, writers face a unique set of constraints. Like the speakers, writers face challenges in transforming experience to representation, in deliberately shaping that representation, in imagining and keeping in mind an audience, and resisting socially sanctioned forms that are inadequate to persuasion. (120)

And this, in no lesser manner, is the case with What is the What for Eggers. In fact, the form of the book, both as a novel and as an autobiography, reveals the struggle of the author with his voice in the narrative. The decision of Eggers to make his voice disappear completely was well worth the effort. It has made the happenings of more things possible for both Eggers and Valentino, including achieving the purpose of reaching a maximum number of audiences.

\section{Theoretical framework}

For the theoretical underpinnings of the article, we rely on Itamar Even-Zohar's (1980) conception in "constraints of realeme insertability in narrative" and Brain McHale's notions of historical realemes in Postmodern Fiction (1987). McHale has defined realemes as a repertoire of things which serves as a system of reference. This repertoire is not made of real things but of signifiers in a system of significations. Thus, a realeme is a collection of semioticized segments in any given time and place. They are mostly the cultural specific and sub-ranges of repertoires may be taken for one genre and type of text and different subsets of repertoires may be selected for some other type of text. The smallest segment in a repertoire was given the name of realeme by Itamar Even Zohar using neologism (Zohar, 1980).

The idea that language is a passive reflection of reality and nature - or the world out therehas been replaced as the semiotic codes are not capable to convey "information on what is inherent in nature, but inevitably conveys information on nature as it is arranged in accordance with the cultural conventions" (Zohar, 1980: 66). This aspect of language is especially at work when analyzing the informata describing the same situation in different languages. The descriptions do not necessarily convey the message that the same "situation" has been dealt because of the arbitrary nature of language and the differences in cultural conventions. Thus, the translational (or transliterational) practices must be aware of the fact that some items (semiotic codes) are insertable in the texts of one culture while the same may not be insertable in the texts of another. Zohar is of the view that translators face the situation when a realeme of one cultural repertory is not insertable into the text of other culture because of non-existence or prohibition in the target culture. The translator, in such a case, when transferring the description of one situation into another language, either completely deletes it or tempers its components in accordance with the available models in the target language, resulting in realemes' replacement, partial deletion and amplification (Zohar, 1980). This can be the case with Eggers who has transliterated Valentino's childhood experiences that were in a language and culture different than his.

Similarly, according to Zohar, it is not important that the narrator might report what has been observed because a person-in-culture is simultaneously using incompatible sub-codes (one language for one purpose and another for other purposes), without violating the structure of the culture in question. Consequently, in such a scenario, what has been observed and narrated may have no connection with the reality or the real world. So, the real, observable and experienceable phenomena (situations) get replaced by fabricated selections (possible worlds) 
from the cultural repertoires available to the narrator (Zohar, 1980). This feature of the narration has been found in quasi-historical representations that are often taken for granted by historians which are basically conventional stylized models rather than the precise descriptions of the real world. And this is what we are looking for in Valentino's quasi-historical and quasifictional narrative.

Moreover, dealing with real life and actual reality in fiction is governed by these realemes that tell as to what extent a writer is free to fictionalize the life and history of real people. McHale has identified some constrains for the insertion of historical realemes in fiction which are given as under:

a) The fictional version of history must not contradict the official record. The word official record is problematic as there are many versions of history but the clue to know the official history is that to see which version is being canonized by the ones in power.

b) Moreover, there are dark areas in the official record which can open windows for fictionalization. Dark areas give a novelist freedom in instances where the history is silent, for example personal life. However, regarding the personal life of the historical characters, there are still two views; one group of critics say it is admissible (can be fictionalized) and the other group holds the opinion that personal life is inadmissible (cannot be fictionalized).

c) The contradiction in official records is yet another room for fictionalization. The contradiction in official history is due to anachronism and provides freedom to the author. But one thing has to be kept in mind that fictionalization must be true to the culture and ethos of the time.

d) The historical fiction must be real because fantastic historical fiction is an anomaly and must be avoided under any circumstance. This can only be achieved when the logic and physics are compatible with the reality of the age, period, culture and language. (McHale, 1987)

Furthermore, realemes are also constrained by a repertory structure and the imposition of additional functions on a realeme is also possible for the fulfilment of purpose other than conveying real world information. In literary narratives, for instance, realemes were supposed to be subjugated to the character of the protagonist. Even minor details of realia were supposed to contribute towards characterization and had to be interpreted this way. The notion had been so adhered to that it virtually constituted the very notion of literariness (Zohar, 1980). In the case of What is the What, the symbolism in colours and meanings associated with the description of scenery have been utilized for the depiction of Valentino's feelings. Such established conventional repertoires can be highly predictable and eventually become devoid of real-world information because these are transferred into sets of prerequisite components for stereotypic relations and representation. And due to their growing conventionalized use, realemes tend more and more to receive secondary functions which gradually devoid them of their referential potentiality. In the text under consideration, we can locate the insertion of conventional realemes, for the representation of Valentino, from the already available repertoires established by the body of literature written about the Lost Boys of Sudan.

\section{Research methodology}

This research study uses the qualitative approaches i.e., description, exploration and analysis 
for the interpretation of the primary text with reference to the prescribed theoretical framework. The qualitative approaches are exploratory and reflective in nature and are based on interpretative and grounded theory in which interpretation is made with reference to four levels of reflective/reflexive methodology. These four levels are mutually embedded and correspond to each other (Alvesson, M. \& Skoldberg, K., 2000). The purpose of the reflective method is to provide base for a researcher's own interpretation in order to generate new perspectives, grounded on the perspectives of other readers and critics (Rentz, 2002). In this regard, the touchstone for us is the writings of Valentino and Eggers. Valentino's Preface to What is the What (2006) is consulted wherein he has articulated the purpose behind writing the book, in order to see whether the book achieves that purpose at the end or not. Furthermore, Eggers self-authored essay "It was just boys walking" (2004), where he has elaborated the genesis of the book and his collaborative working with Valentino, has also been relied on, in order to see whether the text stands loyal to the claims and purpose of the collaborative project or not.

Moreover, the interpretation of constrained realemes in the selected text is liable to address hermeneutic practices of textual interpretation theory. The hermeneutics practices are actually based on the science of interpretation introduced by Paul Recoeur for the understanding of the text from three different levels: explanation, understanding, and appropriation. The first examines the text from within. The second deals with the question who speaks about something in the text. The third level deals with the aspect to interpret the text appropriately. Recoeur calls the three levels as one unit "hermeneutic arc" (1976). Efforts have been made to analyse the text from all three levels so that the hermeneutic arc is achieved.

\section{Analysis and discussion}

What Is the What (2006) is based on the life of Valentino Achak Deng who-along with other Lost Boys - was forced to leave Sudan at the age of six, when he lost track of his family because of the second civil war (1983-2005) in the country ${ }^{3}$. The novel has been written by Dave Eggers who is the co-founder of San Francisco based non-profit organization called Voice of the Witness established in 2004. The purpose of this organization is to bring to light more real-life narratives and stories of marginalized individuals of the society. This organization publishes volumes of oral history. The book is part of that humanitarian project. Valentino got separated from his family when his village became the arena of conflict between the government backed Murahaleen and the rebellious Sudanese

Liberation Army (SLA) during the second civil war of Sudan. Valentino sought shelter in the house of his aunt with his mother, who is frequently identified, throughout the book, with a yellow dress: "the pregnant yellow of a setting sun" (Eggers, 2006: 35). Before their hiding, they heard the screaming of Valentino's aunt, upon hearing which his mother went out for investigation. Valentino never saw her again. He himself is miraculously saved. After that, he migrates to Ethiopia and then to Kenya. The book consists of three parts: part one covers Valentino's experiences in Sudan before he became a refugee, part two is about his years in Ethiopia and part three covers more than a decade of his life in Kenya, while the whole story has been narrated on the day he was mugged in his apartment in the US.

Valentino wants to tell his story and is optimistic - rather, overly - to make a difference by narrating it as many times as he could because of his strong belief in humanity. Although, he got many opportunities of expressing his experiences publicly but there has always been this 
longing to "reach out to a wider audience", in an individual way through a book "as the specific that might illuminate the universal" (Eggers, "It Was Just Boys Walking") ${ }^{4}$. And this is where Eggers comes into the canvas. The book is the result of their collaborative efforts, spanning over several years. In the backdrop of the Valentino's optimism, will this project make any real difference? So far, the answer is both yes and no, but we will know the answer for sure in the pages ahead.

The preface of What is the What has been written by Valentino, the very first line of which reads: "What Is the What is the soulful account of my life: from the time I was separated from my family in Marial Bai to the thirteen years I spent in Ethiopian and Kenyan refugee camps, to my encounter with vibrant Western cultures beginning in Atlanta, to the generosity and the challenges I encountered elsewhere" (Eggers, 20006: xiii). His multiple migrations include the first one to Ethiopia that is hundreds of miles journey from Sudan, making Valentino end up in the refugee camp of Pinyadu. Due to Ethiopia's internal problems, the refugees were driven back to Sudan. The second migration is to Kenya where the parentless children gathered together in the safe boundary of Kakuma Refugee Camp. It was there that Valentino and other roaming boys like him were given the title of the Lost Boys by aid workers, after the companions of Peter Pan in the famous story by J. M. Barrie (1904).

In introduction, we have stated that much of the post-9/11 aesthetics have either been borrowed from or guided by postmodern aesthetics. The very first instance of this claim can be found in the title of the book that is suggestive of a hermeneutic in and out of genres; a postmodern literary technique. The title and sub-title of this humanitarian project, What is the What, the autobiography of Valentino Achak Deng, appears somewhat contradictory. Although, the title claims it to be an autobiography, but Valentino is not the writer. We encounter another contradiction when we see that the publisher has classed the book in the category of fiction, despite the fact that the title claims the contrary. These contradictions raise many questions e.g., if the work is an autobiography, then why it has not been written by Valentino, how come a work be both fiction and autobiography/non-fiction, if it is ghost-written then why does it not bear the name of Valentino for an author. Answering questions like these is in itself too daunting a task befitting the length of a paper but we would stick only to those questions which are directly pertinent to our analysis. In fact, this is a deliberate act on the part of Eggers who has mixed up different genre techniques in his narrative which is, again, suggestive of his subscription to the postmodern aesthetics (a detailed discussion appears later in the section).

The analysis derives its theoretical underpinnings from two sources, as declared in the theoretical framework section: constraints of realeme insrtability by Evven Zohar (1980) and constrained realemes by McHale (1987). On the other hand, preface to the book by Valentino and "It was just boys walking" by Eggers are also important sources as these discuss the collaboration between Valentino and Eggers and also the genesis of What is the What. Eggers points out the difficulties and complexities faced by him while deciding a narrative strategy and genre, as well as the overall structure for the book. As far as the narrative is concerned, the main problem with the recollections of Valentino's early experiences of the civil war, after interviewed by Eggers many times, was that his account did not match with the official history because he was just a boy of six when he started his journey to Ethiopia. That is why his memory of the time is very spotty (Eggers, JBW).

This crosses out possibility of a journalistic book telling the story of Valentino because such 
an attempt would not have transcended the many articles, human right reports, and essays about the lost boys of Sudan (Eggers, JBW). The spotty parts of the memory can rightly be termed the dark areas of Valentino's life - to use McHale's coinage (1987) - that are actually potential sites for an author to fictionalize through imagining as long as the fictionalization does not contradict official history. However, the fictionalization of the dark areas, in case of What is the What, serves to make the story of Valentino in line with the official version of history whereas, originally, dark areas are instances in real people's lives where the official record is silent and the author could fictionalize these as long as these are in line with the official version of history. So, the technique has been utilized by Eggers but a bit differently than its original usage and purpose.

The second option for the book's narrative structure was non-fiction but that, too, was not suitable because the spotty memory of Valentino's life prevented Eggers from inserting any real dialogues in the narrative which are essential for a non-fiction book from a journalistic point of view. Thus, the option was also eliminated after due consideration. Moreover, the third-person narrative had problems of its own because this narrative technique would have created a distance from the events of Valentino's life. Furthermore, it would have also made Eggers very much at the forefront as the author of the book and so the purpose to make the experiences of Valentino the central concern would have shifted to the background. Eggers definitely did not want to do that and finally reaches a conclusion regarding his authorial status in the project, he says:

“... in the book, I knew I had to disappear completely" (Eggers, JBW).

In the preface to the novel, Valentino writes: "Over the course of many years, Dave and I have collaborated to tell my story... I told [him] what I knew and what I could remember, and from that material he created this work of art" (Eggers, 2006: ii). He confirms the happenings in the story and points that he has not known any other picture of Sudan than presented in the book. The problem lies in the fact that its publisher has classified it in the category of fiction but when we look at the sub-title of the memoir, it reads: The Story of Achak Deng. The sub-title is insignificant in face of the category in which the story has been classed because this distinction betrays any chances of Valentino ever claiming to own his story. His real-life story belongs now to another fictional person. The tension created by such hermeneutic deconstruction is at the heart of historical fiction. So, the purpose of the humanitarian project "The Voice of the Witness" to give voice to the marginalized seems to collapse in the case of Valentino as the attempt of recovering his voice actually deprives him of it. His story is a corporate commodity now and his real-life story has become a fictional one in that commodity.

The book is typical of Eggers' style: blending non-fictional and fictional elements into a nonfiction novel or memoir. By classifying the book as a novel, Eggers says "he freed himself to re-create conversations, streamline complex relationships, add relevant detail and manipulate time and space in helpful ways - all while maintaining the essential truthfulness of the storytelling" (Eggers, JBW). This is where the role of constrained realemes comes in to play. It is obvious that Eggers has taken liberties in fictionalizing the dark areas of Valentino's life in Sudan, as well as in America. For example, the September 11 terrorist attack is present as a trope in the novel. Valentino says: "[o]nly forty-six refugees were scheduled to fly to New York on September 11, and one of them was me" (Eggers, 2006: 105). It has been shown that September 11 was the day Valentino was migrating from Kenya to America, along with other 
45 lost boys, when he saw the breaking news bulletin in the airport about the attacks due to which his flight got cancelled. This is the point where the writer has fictionalized the actual day of his arrival to America and its co-occurrence with 9/11. Actually, it was a day of September 2001 but not definitely 9/11. The fictionalization of the event has been carried out for creating a traumatic effect on Valentino's psyche and for bringing a more dramatic effect in Valentino's narrative. The example sufficiently illustrates the freedom and liberty taken by Eggers while portraying the life of the protagonist.

The story is full of traumatic experiences but the first trauma in Valentino's life was the loss of his parents, more especially of his mother's sudden disappearance, and the uncertainty about their life and death was an "ambiguous loss" (Cit: Lester, et el. 245) for Valentino. He is not sure what has happened to his parents. After the incident in his village, he went into a state of denial. The figure of his mother was a surety of safety and comfort for him, and it is very difficult to convey the depth of this bond through ordinary description in the book. That is why Eggers has captured the essence of it through many tropes and symbols; a conventional style in characterization through the insertion of different realemes. The symbolism associated with yellow colour and the setting sun gives the image of the mother, in the mind of a six-year-old child, an aura of omnipresence. This fictionalization is crucial for conveying the strong but indescribable bond between a six-year-old child and his mother. Once the depth of this relationship is depicted, the audience can very well understand the sense of loss and the subsequent trauma Valentino went through after her disappearance. Concomitant upon this were the appearances of false mother-like figures in the life of Valentino that were even more traumatizing and disappointing - perpetuating his trauma.

Valentino encountered the first false mother when the Lost Boys were chased off and driven back into the lap of the war by Ethiopian soldiers. One of the robbers, Powder, triggers that memory which happened during the crossing of Gilo River. He says:

I stare up at Powder and I know who he brings to mind. The soldier, an Ethiopian and a woman shot two of my companions and almost killed me. She had the same wild light in her eyes, and she first posed as our saviour. We were fleeing Ethiopia, chased by hundreds of Ethiopian soldiers shooting at us, the River Gilo full of our blood, and out of the high grasses she appeared. Come to me children! I am your mother! Come to me! ... Two of the boys I was running with, boys I had found on the bank of the river, they both went to her. And when they drew close enough, she lifted an automatic rifle and shot through the chests and stomachs of the boys. They fell in front of me, and I turned and ran. Come back! She continued. Come to your mother! (Eggers, 2006: 6).

The importance of the scene in the context of the story can be guessed from the fact that it is the only scene that appeared twice in the narrative but more importantly for Valentino is the appearance of a false mother figure. The cold-blooded cruelty of the woman seems to have left indelible marks on Valentino's memory. Indeed, he was passing from several other kinds of psychological and physical atrocities, but none seemed as traumatizing as the ambiguous loss of his mother and the appearance of false mother figures was making his trauma even more complex. This has been because each time the new expectations were created and then reshattered the next moment. Thus, it was keeping the wounds of the trauma afresh and not letting them to heal. Eggers has utilized this trauma and the longing of Valentino for his mother as the 
central thread for the whole story because the resonance of it can be seen at several instances in the narrative.

The Gilo River crossing was certainly the most difficult juncture in the Lost Boys' lives. Janice Goodman (2004) has also interviewed 14 Lost Boys, after they were being resettled in the US. In her investigation of the events related to Gilo River crossing, she notes that "all of the participants told a story about it, many of them reported that it was the most traumatic event of their life" (Goodman, 2004: 1185). The difference in the accounts of the fourteen resettled boys is a clue that Eggers has put to work his imagination for the fictionalization of this aspect which sufficiently proves that he has utilized the dark areas of Valentino's life as potential sites for fictionalization.

Moreover, his story has been narrated in the span of a single day; starting from the robbery in Valentino's apartment and the assault he received at the hands of the robbers, continues at the hospital while he was seeking medical help and ends up in his apartment. This technique has been adopted as a literary narrative style and has been borrowed from James Joyce's A Portrait of the Artist as a Young Man (1922). We also see another mixing of genres that is the blend of modern fictional narrative tradition with the Sudanese Oral Narrative tradition. Valentino was narrating his story in the Sudanese oral tradition which was deep rooted in him, and its influence could not have been expelled from the narrative. The flavour gives the story an aura of authenticity but at the same time it could not be incorporated in the book as a whole because Eggers found out, during the recording sessions with Valentino, that "there were great limitations, in this case, to the oral history model" (Eggers, JBW).

Zohar (1980) refers to this aspect as the constraint of realeme insertability when a realeme is not insertable into the text of another culture. The author then adopts transliterational strategies to overcome the limitation. Consequently, in such a scenario, what has been observed and narrated may have no connection with the reality or the real world. So, the real, observable and experienceable phenomena (situations) get replaced by fabricated selections (possible worlds) from the cultural repertoires available to the narrator. That is why Eggers has blended the oral tradition with the modern fictional narrative tradition by blurring the boundaries between the world of fiction and the world of reality and has created, as has been referred to by McHale (1987), this double-dicker structure of reference that might have no connection with Valentino's real experiences in Sudan. That is why the book is not entirely a novel nor is it a memoire and nor an autobiography either because of the blend of fact and fiction that has allowed for Eggers' hermeneutic playfulness between different genre traditions.

\section{Conclusion}

It is easy to say, straight away, that Eggers has fictionalized few dark areas of Valentino's life and the fictionalization has no contradiction with the official version of history but, contrary to the theorization of McHale about the dark areas, Eggers has inverted the theorization to meet his requirements. He had to make the spotty memory of Valentino's life in line with the official history of the Lost Boys and not the other way around. So, he has played with the early childhood narrative of Valentino in order to make it aligned with the official version by removing certain contradictions in it. Moreover, he has mixed up fiction and history by blurring the boundaries between the two, by making a useful use of his artistic acumen. He has achieved the effect in his book by mixing the techniques of different genre traditions e. g. Sudanese oral 
tradition and American fiction tradition and also by replacing the realemes of Sudanese oral tradition with realemes of American fiction tradition.

Being classified in the post-9/11 fiction, there is enough evidence of borrowing from postmodern aesthetics. The very first aspect is the book's resistance towards classification in the already existing genres - rather it indicates at the inauguration of a new genre tradition where we can observe a hermeneutic playfulness of postmodern and 9/11 fiction aesthetics at paly. But not all critics agree and appreciate Eggers for the effort as Lee Siegel sees as much of Eggers in the novel as Valentino, unable to tell the two apart, saying "[h]ow strange for one man to think that he could write the story of another man, a real living man who is perfectly capable of telling his story himself - and then call it an autobiography." (Siegel, 2007, p. 3). Valentino has always wanted to recount his story through a book, but he realized at some point that his language skills are not proficient enough to turn his dream into reality that's why Eggers' help was sought for. The genesis of the project, as discussed in the methodology, has sufficiently revealed the hardships faced by Eggers and Valentino and the efforts they had to put in to overcome all the hurdles, undermine such criticism.

The work is a true example of testimonio, a hybrid fictional genre where the author uses the testimonies and confessional tales of the victims for telling their narratives. It is the most suitable authorial strategy for bringing to light the marginalized narratives of people like Valentino who are unable to recount their own stories. Through such conscious and politically charged efforts, they become able to earn the status of agency because they acquire their own standpoint. Their agentic position further enables them to reach out to millions of audiences and make a difference in the real sense of the term. Thus, we see the initial purpose of Valentino, as outlined in the preface, has been achieved because the story of the Sudanese Lost Boys has reached millions of readers, informing and educating them about the conflict zone and also clearing their minds off the cobwebs created by the previous stereotypes and (mis)representations.

Above all, the book is a remarkable piece of literature and a true work of art where the "truth is subservient to the book's more urgent message, which is grander than any experience of any single person" (Baudrillard, 2010: 133). In order to achieve this artistic and political purpose, Valentino himself becomes a character in a fictionalized version of his own life story that legally belongs to someone else. Throughout the novel, Valentino tries to tell his story, but we are not sure whether anyone is listening, or the narration goes inside his own mind. So, narrating his story and still not telling or the absence of any real interlocutor is a phenomenon beautifully depicted by Eggers.

This could be another site in What is the What for further exploration because the presence of an empathetic listener/reader is an essential feature for a testimonio in order to be truly effective as it is a politically charged and a highly engaging genre. We suggest to the researchers interested in the novel to analyse the issue of fictional and real addressees in What is the What, the theoretical aspects of which have been covered by Nance (2006) in her book on the testimonio and from the aspect of trauma, Cathy Caruth (1996) may also be consulted who insists on the importance of people listening to and reading the accounts of traumatic histories in the healing process. 


\section{References}

Alvesson, M., \& Sköldberg, K. (2000). Reflexive methodology: New vistas for qualitative research. Sage.

Apple, M. (1976). The Oranging of America, and other stories. Grossman.

Barrie, J M, Zipes, J., Barrie, J M. \& Barrie, J M. (2004). Peter Pan. Penguin Books.

Baudrillard, J. (2010). America. Verso.

Caruth, C. (1996). Unclaimed experience: Trauma, narrative, and history. Johns Hopkins University.

Coover, R. (1977). The public burning. Viking.

Doctorow, E. L. (1975). Ragtime. Random House.

Eggers, D. (2006). What is the what: The autobiography of Valentino Achak Deng: a novel. McSweeney's.

Eggers, D. (May 26, 2007). It was Just Boys Walking. Guardian.

Even-Zohar, I. (1980). Constraints of Realeme Insertability in Narrative. Poetics Today, 1(3), 6574. https://doi.org/10.2307/1772411

Gray, A. (1984). Unlikely stories, mostly. Penguin Books.

Joyce, J. (1922). A portrait of the artist as a young man. B.W. Huebsch.

Luster, T., Qin, D. B., Bates, L., Johnson, D. J. \& Rana, M. (2008). The Lost Boys of Sudan: Ambiguous Loss, Search for Family, and Reestablishing Relationships with Family Members. Family Relations 57: 444-456. https://doi.org/10.1111/j.17413729.2008.00513.x

McHale, B. (1991). Postmodernist Fiction. Routledge.

Miller, S. L., \& Rentz, K. (1999). Book Reviews: Discourse and Organization. Edited by David Grant, Tom Keenoy, and Cliff Oswick. London: Sage, 1998. 248 pages. The Journal of Business Communication (1973), 36(4), 419422.

Montejo, E., Barnet, M., \& Rowlandson, W. (2010). Biografía de un cimarrón. Manchester University.

Moulthrop, D., Calegari, N. C., \& Eggers, D. (2006). Teachers have it easy: The big sacrifices and small salaries of America's teachers. New Press.

Nance, K. A. (2006). Can literature promote justice? Trauma narrative and social action in Latin American testimonio. Vanderbilt University.

O'Gorman, D. (2015). Fiction on the war on terror: Difference and the Transnational 9/11 Novel. Palgrave.

Pynchon, T. (1973). Gravity's rainbow. Viking Press.

Ricœur, P. (1976). Interpretation theory: Discourse and the surplus of meaning. Texas Christian University.

Siegel, L. (2007, April 19). Rew: "The Niceness Racket". The New Republic.

Sheikh, S. (2020). To Clarify: Teachers are not off for Summer, They are in Recovery. Independently Published.

Thompson, B. (2006, November 28). "A Heartbreaking Work of Fiction". Washington Post. 
Real, compared to what? Insertability of constrained realemes in Dave Eggers' What is the What

Notes:

${ }^{1}$ Appeared on McSweeney's website without bibliographic information. http://www.mcsweeneys.net/books/teachers.html.

2 The book has been cited as a passing reference and has not been reviewed as it is not in the category of relevant literature but an inspirational read for people interested in the topic.

${ }^{3}$ The second civil war can be seen as an extension of the first Sudanese Civil War (1955-72) with a temporary peace agreement in between that lasted for 11 years.

${ }^{4}$ From here onward, "It was just boys walking" will be written as JBW in all in-text entries.

JHSMS, 2021, 2(2), 240-254

254 